\title{
Determining the Accuracy of Blood Pressure to Height Ratio as a Screening Tool for Hypertension among Egyptian Children
}

\author{
${ }^{1}$ Shereen M. Bahgat, ${ }^{2}$ Soad A. Shedeed, ${ }^{1}$ Aya M. Abd El Hamid, ${ }^{2}$ Ahmed Elhewala \\ ${ }^{1}$ Department of Family Medicine, ${ }^{2}$ Department of Paediatric Medicine Faculty of \\ Medicine, Zagazig University, Zagazig, El-Sharkia, Egypt
}

Received: June, 2018 Accepted: August, 2018

\begin{abstract}
Background: Hypertension diagnosis in children is difficult because of the multiple sex, age, and height-specific thresholds to define elevated blood pressure (BP). Blood pressureto-height ratio (BPHR) has been used to facilitate the identification of elevated BP in children. Methods: From January to June 2017, a cross-sectional study was conducted for 830 adolescents aged 12 to 15 years in Abu Kabir city, Sharkia governorate, Egypt. Blood pressure tables from the National High Blood Pressure Education Program (NHBPEP) Working Group on High Blood Pressure in Children and Adolescents were used as our standard of comparison. Sex-specific systolic and diastolic blood pressure-to-height ratios (SBPHR and DBPHR) were calculated. Receiver operating Characteristic (ROC) curve analyses were performed to assess the accuracy of BPHR for discriminating between hypertensive and non-hypertensive adolescents. Results: The prevalence of prehypertension and hypertension were $8.4 \%$ and $4.9 \%$ respectively. Optimal SBPHR and DBPHR thresholds for defining elevated BP were 0.741 and 0.475 in males, respectively, and 0.750 and 0.494 in females, respectively. The sensitivity of SBPHR and DBPHR in both sexes was all above 93\%, and specificity in both sexes was above 94\%. Positive predictive value for SBPHR and DBPHR was $76.4 \%$ for both in males; and $71.4 \%$ and $71.6 \%$ in females respectively; negative predictive values in both sexes were all above 98\%. Conclusions: BPHR is a simple screening tool with high sensitivity and specificity for screening hypertension in adolescents.
\end{abstract}

Keywords: Adolescents; Blood pressure to height ratio; Hypertension; Screening.

Correspondence to Dr. Shereen M. Bahgat; Email: drshereenbahgat@ yahoo.com

\section{Introduction}

Hypertension is a worldwide health problem affecting substantial proportion of the world population. It is known that increased blood pressure becomes established since childhood. ${ }^{1}$ In the US, about $1 \%$ to $5 \%$ of children had hypertension while about $12 \%$ to $17 \%$ had prehypertension. ${ }^{2}$ In Egypt, the prevalence rates of hypertension and prehypertension are $4 \%$ and $5.7 \%$, respectively. ${ }^{3}$ Current diagnosis of hypertension in children is done by comparing the child blood pressure with tabulated reference values of the $50^{\text {th }}$, $90^{\text {th }}, 95^{\text {th }}$, and $99^{\text {th }}$ percentiles the age-, gender-, and height- matched population. $^{4}$ To diagnose hypertension in children and adolescents, the systolic blood pressure (SBP) and/or the diastolic blood pressure (DBP) should be higher than the $95^{\text {th }}$ percentile. While in prehypertension, the blood pressure SBP should be between the $90^{\text {th }}$ and $95^{\text {th }}$ percentile for age, sex, and height. ${ }^{5}$ Hypertension is considered a risk factor for many diseases as cardiovascular and 
renal diseases. ${ }^{6}$ Elevated BP in children can predict hypertension in adulthood and is associated with many complications as left ventricular hypertrophy and carotid intimal medial thickness. ${ }^{7,8}$ Therefore, the identification of children with elevated BP is important for proper management of childhood elevated blood pressure and therefore, preventing its complications. ${ }^{9}$

However, in paediatric outpatient clinics, it is difficult to use this current method of diagnosing elevated blood pressure based on sex-, age-, and height- matched reference values with multiple cut off points for prehypertension and hypertension diagnosis. ${ }^{10}$

In 2011, Lu et al. ${ }^{11}$ first reported that blood pressure to height ratio (BPHR) can simply and accurately identify hypertension in children in China. ${ }^{11}$ Their observations have also been confirmed by studies done in other populations. $^{12}$ Multiple worldwide studies have been recently conducted to investigate the accuracy of diagnosing BPHR in children population. However, to the best of our knowledge, no similar studies have been conducted in Egypt.

\section{Method}

We followed the Strengthening the Reporting of Observational Studies in Epidemiology (STROBE) statement guidelines when reporting this manuscript. ${ }^{13}$ The study was approved by the institutional review board of Faculty of Medicine, Zagazig University, ElSharkia, Egypt (approval no. 3287/3-12017). In addition, we obtained a regulatory permission from the Directorate of Education in Abu Kabir city to conduct this study.

Study Design, Setting, and Duration: We conducted a cross-sectional study in five preparatory schools in Abu Kabir city, El-Sharkia, Egypt. The study was conducted within the period from January to June 2017.
Eligibility Criteria: From Abu Kabir city, Sharkia governorate, Egypt, we included preparatory school students of both genders with an age ranging from 12 to 15 years.

We excluded students with any known medical conditions that might cause secondary hypertension or those who are using any drugs that might cause secondary hypertension.

Sample Size Calculation: We calculated the required sample size according to the equations and tables of Buderer et al. $1996 .{ }^{14}$

$T P+F N=Z^{2} x \frac{\text { Sensitivity }(1-\text { Sensitivity) }}{W^{2}}$

$T N+F P=Z^{2} x \frac{\text { Specificity }(1-\text { Specificity) }}{W^{2}}$

Where Z, the normal distribution value, was set to 1.96 as corresponding with the 95\% confidence interval, $\mathrm{W}$, the maximum acceptable width of the $95 \%$ confidence interval, was set to $10 \%$, and the expected sensitivity and specificity were set to $90 \%$ based on estimates from previous studies $\mathrm{TP}+\mathrm{FN}=34.5, \mathrm{TN}+$ $\mathrm{FP}=34.5$

$\mathrm{N}$ required for sensitivity

$=\frac{T P+F N}{P}=\frac{34.5}{0.05}=691$ participants

(where $\mathrm{P}$, the expected prevalence of hypertension, was set to $5 \%$, as reported by previous studies. ${ }^{3}$

$\mathrm{N}$ required for specificity

$=\frac{T N+F P}{1-P}=\frac{34.5}{1-0.05}=36$ participants

(where $\mathrm{P}$, the expected prevalence of hypertension, was set to $5 \%$, as reported by previous studies. ${ }^{3}$ Total required sample size $=691+36=728$ participants 
Sampling Method: We performed a probability sampling method using the multistage clustered random sampling technique. Out of the 65 preparatory schools in Abu Kabir city, five schools were selected randomly. Then, from each grade of the selected schools $\left(1^{\text {st }}, 2^{\text {nd }}\right.$ or $3^{\text {rd }}$, we selected one class randomly. All students in the selected class were included in the study.

Data Collection and Outcome Measurements: The research team collected the data by themselves assisted by some medical trainees from Zagazig University Hospitals. Participating trainees received a standard training of blood pressure measurement for adolescents and weight and height measurement. The case record forms were printed as hard copies and were filled manually by the researchers during the schools' visits. At the end of the data collection phase, all data were entered manually to a Microsoft Excel sheet for statistical analysis.

The collected data included the following measurements for each participant:

\section{Body weight}

We measured body weight of the study participants using a balance scale while wearing minimal clothes and with bare foot. The balance scale was placed on a hard-flat surface and zero balance was ensured before measurement. Weight was recorded to the nearest $0.5 \mathrm{~kg}$ as suggested previously. ${ }^{15}$

\section{Height}

For all participants, we measured the height in standing position. The reading was recorded in centimetres, to the nearest $5 \mathrm{~mm}$ as suggested previously. ${ }^{15}$ For all participants, height was measured without shoes with the back bone against the wall, the line should be at the angle of the eye and ear tragus is horizontal and a mark on the wall was done at that level. The distance between the mark on the wall and the floor was measured by a scaled tape. ${ }^{16}$

\section{Body Mass Index}

The body mass index (BMI) was calculated based on the measures of weight and height according to the following equations:

$B M I=$ Weight $(\mathrm{kg}) / \mathrm{Height}(\mathrm{m})^{2}$

\section{Blood pressure}

The auscultatory method of BP measurement was used with mercurial sphygmomanometer and stethoscope according to the recommendation of the National High Blood Pressure Education Program Working Group in Children and Adolescents. ${ }^{17}$

The cuff bladder width covered $50 \%$ to $75 \%$ of the circumference of the arm, BP measurements were taken at least 5 minutes after resting.

SBP was defined as the first Korotkoff sound and DBP as the fifth Korotkoff sound.

In addition, prehypertension was defined as either SBP/DBP greater than or equal to the referent sex, age, and height specific $90^{\text {th }}$ percentile or SBP/DBP $\geq 120 / 80 \mathrm{~mm} \mathrm{Hg}$, and hypertension was defined as SBP/ DBP $\geq 95^{\text {th }}$ sex-, age-, and height-specific percentile according to the references of the NHBPEP working group. Sex- and age-specific percentiles of height were derived from the Egyptian growth chart. ${ }^{17}$

\section{Statistical analysis}

Data were summarized as mean \pm standard deviation for quantitative variables and frequencies and percentages for qualitative variables. The sensitivity, specificity, positive predictive value (PPV), negative predictive value (NPV), and AUC (95\% CI) were calculated to assess the performance of determined optimal thresholds. The likelihood ratios (positive $[\mathrm{LR}+]$ and negative $[\mathrm{LR}-]$ ) were also computed in our study. The $\mathrm{LR}+$ of a positive test result is sensitivity divided by $1-$ specificity and indicates how much the odds of a disease increase when a test is positive. Conversely, the 
LR - indicates 1 - sensitivity divided by specificity and indicates how much the odds of a disease decrease when a test is negative. The area under the curve (AUC) and 95\% confidence interval (CI) for the BPHR index, calculated by ROC curve analysis, were used to assess the discriminatory power of a test. The AUC typically ranges from 0.5 to 1 , representing a test that has poor discrimination to 1 that has perfect discrimination. To determine the optimal thresholds of the BPHR index for identifying elevated $\mathrm{BP}$, the values corresponding to the maximum of Youden's index (sensitivity + specificity - 1) were selected. Prehypertension and hypertension were then redefined by the determined optimal thresholds of the BPHR index and were used as predictive variables to compare with the gold standard. Data were handled using appropriate statistical tests of significance such as: t-test was used to investigate the differences among means and chi square for qualitative data. An alpha level below 0.05 was considered for statistical significance. Analyses were done using the Statistical Package of Social sciences (SPSS) software program version 20.

\section{Results}

Characteristics of the study population Our study included 830 children. Of them, 285 were males while 454 were females. The prevalence rates of prehypertension and hypertension in the study population were $8.4 \%$ and $4.9 \%$ respectively. The characteristics of the study population, categorized by gender, are shown in Table 1. Males were significantly taller than females $(P<0.001)$. Both SBP and DBP were significantly higher in males than females

$(\mathrm{P}<0.01)$.

Table 1. Age, weight, height, BMI, SBP, DBP, SBP/H, and DBP/H of the study population by gender

\begin{tabular}{|l|l|l|l|}
\hline Variable & $\begin{array}{l}\text { Males } \\
(\mathbf{n = 2 8 5})\end{array}$ & $\begin{array}{l}\text { Females } \\
(\mathbf{n = 5 4 5})\end{array}$ & P value \\
\hline Age: $($ year) & $13.66 \pm 0.90$ & $13.53 \pm 0.91$ & $0.07 \mathrm{NS}$ \\
\hline Weight: $(\mathrm{Kg})$ & $53.44 \pm 14.83$ & $55.57 \pm 12.91$ & $0.04^{*}$ \\
\hline Height: $(\mathrm{m})$ & $1.55 \pm 0.99$ & $1.52 \pm 0.66$ & $<0.001^{*}$ \\
\hline BMI: $(\mathrm{Kg} / \mathrm{m} 2)$ & $22.04 \pm 5$ & $23.85 \pm 4.73$ & $<0.001^{*}$ \\
\hline SBP: $(\mathrm{mmHg})$ & $106.12 \pm 11.73$ & $103.72 \pm 11.26$ & $0.005^{*}$ \\
\hline DBP: $(\mathrm{mmHg})$ & $67.29 \pm 8.47$ & $65.74 \pm 8.82$ & $0.01^{*}$ \\
\hline SBPHR: $(\mathrm{mmHg} / \mathrm{cm})$ & $0.69 \pm 0.07$ & $0.68 \pm 0.07$ & $0.51 \mathrm{NS}$ \\
\hline DBPHR: $(\mathrm{mmHg} / \mathrm{cm})$ & $0.43 \pm 0.05$ & $0.43 \pm 0.06$ & $0.55 \mathrm{NS}$ \\
\hline
\end{tabular}

All values are expressed as mean $\pm S D ; *$ Statistically significant; NS=not significant; BMI=Body Mass Index; SBP=Systolic Blood Pressure; DBP=Diastolic Blood Pressure; SBPHR=Systolic Blood Pressure to height ratio; DBPHR=Diastolic Blood Pressure to height ratio

Blood pressure levels between the study groups

Both SBP and DBP were significantly lower in females than males (Figure 1A).
However, the SBPHR and DBPHR did not differ significantly between the two groups (SBPHR: 0.69 vs. $0.68, P=0.51$ 
and DBPHR: 0.43 vs. $0.43, P=0.55$;

Figure 2B).

Results of the correlation analysis

Correlation analysis showed that both

SBP and DBP were significantly

Table 2. Correlation between age, BMI, and blood pressure within the study population

\begin{tabular}{|c|c|c|c|c|c|c|c|}
\hline \multicolumn{2}{|c|}{ Variable } & Age & BMI & SBP & DBP & SBP/H & DBP/H \\
\hline \multirow{2}{*}{ BMI } & $\mathrm{R}$ & $0.25 *$ & ---- & $0.11 *$ & $0.08 *$ & 0.06 & 0.04 \\
\hline & $\mathrm{P}$ & $<0.001$ & & 0.001 & 0.01 & 0.08 & 0.22 \\
\hline \multirow{2}{*}{ SBP } & $\mathrm{R}$ & $0.21 *$ & $0.11 *$ & ---- & $0.89 *$ & $0.87^{*}$ & $0.77 *$ \\
\hline & $\mathrm{P}$ & $<0.001$ & 0.001 & & $<0.001$ & $<0.001$ & $<0.001$ \\
\hline \multirow{2}{*}{ DBP } & $\mathrm{R}$ & $0.26^{*}$ & $0.08 *$ & $0.89 *$ & ---- & $0.78 *$ & $0.91 *$ \\
\hline & $\mathrm{P}$ & $<0.001$ & 0.01 & $<0.001$ & & $<0.001$ & $<0.001$ \\
\hline \multirow{2}{*}{$\mathrm{SBP} / \mathrm{H}$} & $\mathrm{R}$ & 0.05 & 0.06 & $0.87 *$ & $0.77 *$ & ---- & $0.87 *$ \\
\hline & $\mathrm{P}$ & 0.18 & 0.08 & $<0.001$ & $<0.001$ & & $<0.001$ \\
\hline \multirow{2}{*}{ DBP/H } & $\mathrm{R}$ & $0.13^{*}$ & 0.04 & $0.77 *$ & $0.91 *$ & $0.87 *$ & ---- \\
\hline & $\mathrm{P}$ & $<0.001$ & 0.22 & $<0.001$ & $<0.001$ & $<0.001$ & \\
\hline
\end{tabular}

* Statistically significant; BMI=Body Mass Index; SBP=Systolic Blood Pressure; DBP=Diastolic Blood Pressure; $S B P / H=S y s t o l i c$ Blood Pressure to height ratio; $D B P / H=D i a s t o l i c$ Blood Pressure to height ratio

Table 3. Diagnostic accuracy parameters of SBPHR and DBPHR at the optimum cut-off values obtained by ROC curve analysis.

\begin{tabular}{|c|c|c|c|c|c|c|c|c|}
\hline Sex & BPHR & $\begin{array}{l}\text { Sensi- } \\
\text { tivity }\end{array}$ & PPV & $\begin{array}{l}\text { Specif- } \\
\text { icity }\end{array}$ & NPV & AUC $(95 \% \mathrm{CI})$ & PLR & NLR \\
\hline \multirow{2}{*}{ 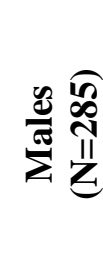 } & $\begin{array}{c}\text { SBPHR } \\
0.741\end{array}$ & $\begin{array}{c}42 / 45 \\
(93.3 \%)\end{array}$ & $\begin{array}{c}42 / 55 \\
(76.4 \%)\end{array}$ & $\begin{array}{l}227 / 240 \\
(94.6 \%)\end{array}$ & $\begin{array}{l}227 / 230 \\
(98.7 \%)\end{array}$ & $\begin{array}{c}0.972 \\
(0.954-0.991)\end{array}$ & 17.3 & 0.07 \\
\hline & $\begin{array}{c}\text { DBPHR } \\
0.475\end{array}$ & $\begin{array}{c}43 / 45 \\
(95.6 \%)\end{array}$ & $\begin{array}{c}43 / 57 \\
(75.4 \%)\end{array}$ & $\begin{array}{l}226 / 240 \\
(94.2 \%)\end{array}$ & $\begin{array}{l}226 / 228 \\
(99.1 \%)\end{array}$ & $\begin{array}{c}0.980 \\
(0.966-0.994)\end{array}$ & 16.5 & 0.04 \\
\hline \multirow{2}{*}{ 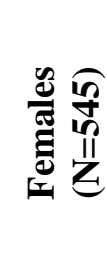 } & $\begin{array}{c}\text { SBPHR0. } \\
750\end{array}$ & $\begin{array}{c}65 / 66 \\
(98.5 \%)\end{array}$ & $\begin{array}{c}65 / 91 \\
(71.4 \%)\end{array}$ & $\begin{array}{l}453 / 479 \\
(94.6 \%)\end{array}$ & $\begin{array}{l}453 / 454 \\
(99.8 \%)\end{array}$ & $\begin{array}{c}0.990 \\
(0.983-0.997)\end{array}$ & 18.2 & 0.02 \\
\hline & $\begin{array}{c}\text { DBPHR } \\
0.494\end{array}$ & $\begin{array}{c}63 / 66 \\
(95.5 \%)\end{array}$ & $\begin{array}{c}63 / 88 \\
(71.6 \%)\end{array}$ & $\begin{array}{l}454 / 479 \\
(94.8 \%)\end{array}$ & $\begin{array}{l}454 / 457 \\
(99.3 \%)\end{array}$ & $\begin{array}{c}0.984 \\
(0.975-0.992)\end{array}$ & 18.4 & 0.05 \\
\hline
\end{tabular}




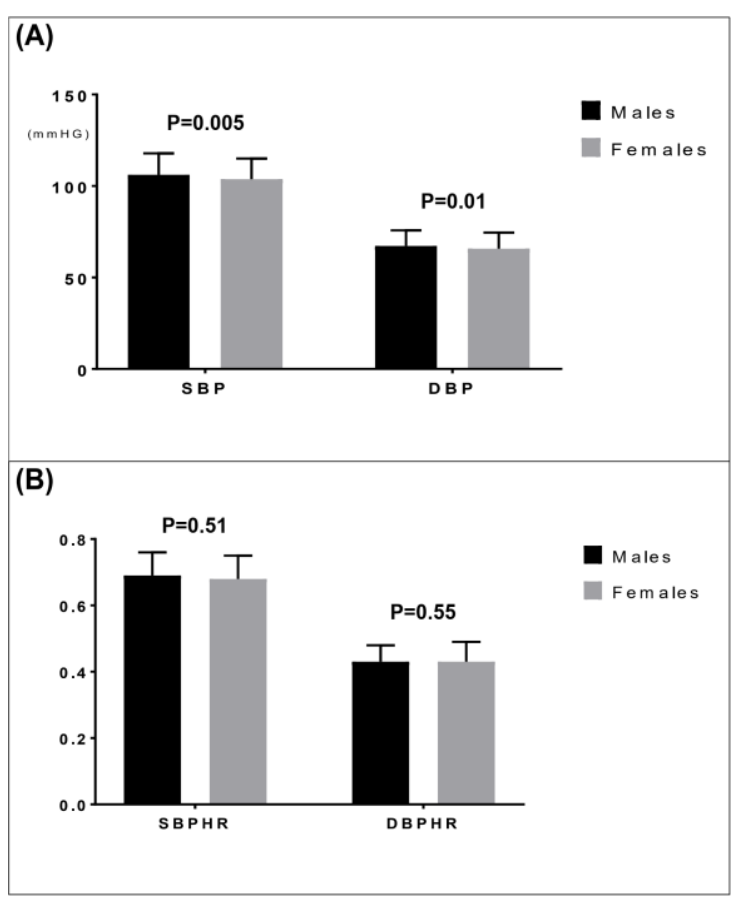

Figure 1 Mean and standard deviation of: (A) SBP and DBP and (B) SBPHR and DBPHR by gender.

Diagnostic accuracy of the SBPHR and DBPHR: For the SBPHR, a cut-off value of 0.741 provided sensitivity and specificity of $93.3 \%$ and $94.6 \%$ respectively among males. While a cutoff value of 0.75 provided a sensitivity and specificity of

$98.5 \%$ and $94.6 \%$ respectively among females (Figure 2).

For the DBPHR, a cut-off value of 0.475 provided a sensitivity and specificity of $95.6 \%$ and $94.2 \%$ respectively among males while a cut-off value of 0.494 provided a sensitivity and specific of $95.5 \%$ and $94.8 \%$ respectively among females (Figure 3).

These optimum cut-off values provided AUCs $>97 \%$ (Table 3). The positive and negative predictive values and the positive and negative likelihood ratios are shown in Table 3.

\section{Discussion}

Our study showed that a SBPHR and DBPHR provided high accuracy in screening school age children for prehypertension or hypertension. Our Figure 2 shows the accuracy of SPBHR

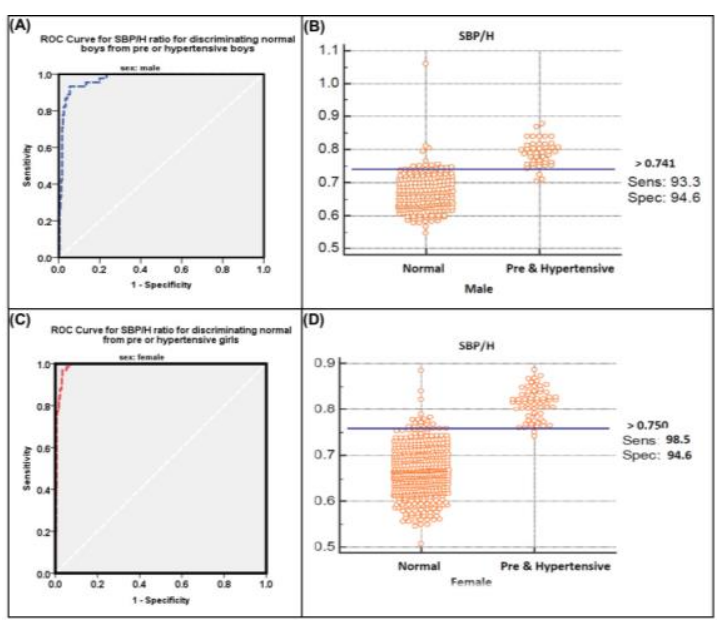

ratio in discriminating normal individuals from pre- or hypertensive individuals: (A) ROC curve in male population, (B) Nomogram in male population, (C) ROC curve in female population, and (D) Nomogram in female population

Figure 3 shows the accuracy of DPBHR

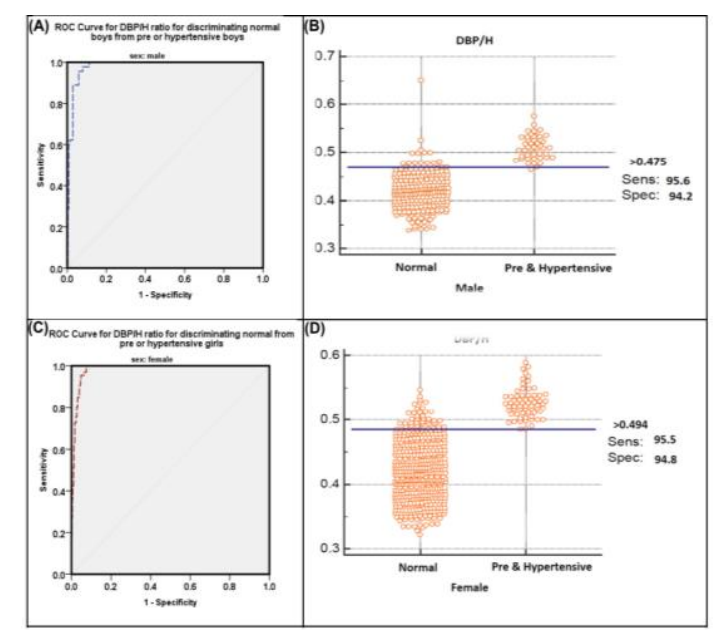

ratio in discriminating normal individuals from pre- or hypertensive individuals: (A) ROC curve in male population, (B) Nomogram in male population, (C) ROC curve in female population, and (D) Nomogram in female population

findings suggest that the optimum cut-off values of SBPHR and DBPHR were 0.741 and 0.475 in males and 0.750 and 0.494 in females. The high negative predictive values of 98.7 and 99.8 in our study imply that adolescents with BPHR below the cut-off point are unlikely to 
have hypertension. However, the low positive predictive values of 76.4 and 71.4 suggest that some adolescents might be misclassified by the test as positive (high BPHR above the cut-off point) while they do not have hypertension. ${ }^{18}$ Taking together the high NPV and the low PPV, we suggest that BPHR can be used as a screening tool and cannot replace existing nomograms for diagnosing or classifying the severity of hypertension.

Unlike sensitivity and specificity, the predictive values are influenced by the prevalence of the disease in the study population. Therefore, a patient with positive test result is likely to be diseased if the disease is common in the study population and vice versa. Because the prevalence of hypertension is low in children, the PPV were low in our study as well as in previous studies. ${ }^{19,20}$

The rise of $\mathrm{BP}$ with increasing age is most probably caused by the growth of the child. Blood pressure in children is related to somatic growth and is tied to increase in height, skeletal maturation and sexual maturation. Also, body size exerts a profound influence on a variety of physiological functions, including BP and the onset of puberty, this interrelated effect of maturation, growth, body weight and body fat are influenced by both genetic and environmental factors.

Our BPHR cut-off points for defining elevated blood pressure were close to estimates of a previous study in the USA where the cut-off value of SBPHR for both males and females was $0.75 .^{21}$ The DBPHR cut-off values of 0.46 and 0.48 for males and females, respectively, offered sensitivity and specificity of $>80 \%$ which is close to our findings. This US study was based on data of 3775 children retrieved from the NHANES database (2006-2007). Therefore, this study is different from our study in the location, population genetics and race, data source, sample size, and sampling method.

Our study is in line with the findings of Dong et $a .^{22}$ who could discriminate children with prehypertension from those with normal blood pressure at cut off points of 0.75 and 0.46 for the SBPHR and DBPHR, respectively. ${ }^{22}$

A third study showed that the optimal SBPHR cut-off values for diagnosing systolic prehypertension were 0.75 and 0.76 in males and females, respectively (19). While the optimal DBPHR values to diagnose diastolic prehypertension were 0.47 for males and 0.48 for females with a sensitivity and specificity of $>80 \% .^{19}$

And according to Lu et al. ${ }^{11}$ the optimal thresholds of SBPHR and DBPHR for identification of prehypertension in adolescents were 0.75 and 0.48 for males and 0.78 and 0.51 for females respectively with a sensitivity and specificity $>90 \%$.

It is known that both blood pressure and height are influenced by genetic and racial factors. Therefore, the slight differences between our study and the previous studies in terms of the cut off values and test sensitivity and specificity can be explained by the difference in race, genetic factors, and sampling method.

Our study showed statistically significant differences between males and females in terms of weight, height, SBP and DBP. Males were older and taller than females while female had more weight and BMI. Both SBP and DBP were higher in males than females. This was further supported by previous studies. ${ }^{23,24}$ Amin et $a l .{ }^{23}$ found that females had higher BMI compared to males $(19.1 \pm 3.5$ vs. $\left.18.4 \pm 2.5 \mathrm{~kg} / \mathrm{m}^{2} ; P=0.001\right)$. In addition, males were taller than females $(137.5 \pm 14.9$ vs. $136.8 \pm 15.6 \mathrm{~cm} ; P=0.5)$. In our study, the SBPHR and DBPHR were significantly correlated with the SBP and DBP which is supported by the 
results of Ambarita et al. ${ }^{25}$ They found significant correlations between SBPHR/DBPHR and SBP/DBP $(P<0.05)$; SBPHR and SBP, as well as DBPHR and DBP, had strong, positive correlations.

The same results were reported by Guo et $a l .{ }^{26}$ who found that there was a significant positive correlation between the SBPHR and SBP percentiles $(r=0.716$ for five to 12 years old and $\mathrm{r}=0.882$ for 13 to 18 years old; $P<0.001)$. Similarly, the DBPHR was positively correlated with the DBP percentiles $(\mathrm{r}=0.819$ for five to 12 years old and $r=0.913$ for 13 to 18 years old; $P<0.001)$. Several subsequent studies confirmed these correlations. ${ }^{16,19,21,27}$

The statistically significant correlation between SBP and age $(P<0.001)$ is consistent with the results of Amin et $a l .{ }^{23}$ who found significant positive correlations between SBP and age in children. However, they did not find a significant correlation between DBP and age of the child unlike our results. This correlation was also found in previous studies. ${ }^{24,28}$

The properties of a diagnostic or screening test are often described using sensitivity and specificity or predictive values as described in our study. Likelihood ratios are alternative statistics for summarizing diagnostic accuracy which are more useful from a clinical point of view. LR is a way to incorporate the sensitivity and specificity of a test into a single measure. Since sensitivity and specificity are fixed characteristics of the test itself, the likelihood ratio is independent of the prevalence of the disease in the population. Likelihood ratios above 10 and below 0.1 are considered to provide strong evidence to rule in and rule out the diagnoses, respectively. ${ }^{29,30}$

In our study, LRs of the SBPHR and DBPHR met the requirements mentioned earlier. In males, PLRs were 17.3 and
16.5 for SBPHR and DBPHR, respectively while in females, the PLRs were 18.2 and 18.4 for SBPHR and DBPHR, respectively. Similarly, the NLRs were all below 0.01 suggesting a strong evidence that the screening accuracy of the BPHR is of clinical importance.

Our study has several strength points: (1) the probability sampling method used in our study increases the generalizability of the study results and enhances the external validity of our findings; (2) the relatively large sample size provides high statistical power for the present analysis, and (3) the standardized measurement of height, weight, and BMI among the study population.

\section{Conclusions}

Our study showed that a SBPHR and DBPHR provided high accuracy in screening school age children for hypertension. Our findings suggest that the optimum cut-off values of SBPHR and DBPHR were 0.741 and 0.475 in males and 0.750 and 0.494 in females. However, owing to the relatively low PPV, we suggest that BPHR can be useful as a screening method for hypertension among school-aged children. Children with positive test results should subject to further evaluation for hypertension.

\section{References}

1. Balagopal PB, de Ferranti SD, Cook S, Daniels SR, Gidding SS, Hayman LL, et al. Nontraditional risk factors and biomarkers for cardiovascular disease: mechanistic, research, and clinical considerations for youth: a scientific statement from the American Heart Association. Circulation. 2011;

2. Moyer VA. Screening for primary hypertension in children and adolescents: U.S. preventive services task force recommendation statement. Ann Intern Med. 2013;

3. Abolfotouh MA, Sallam SA, Mohammed 
MS, Loutfy AA, Hasab AA. Prevalence of Elevated Blood Pressure and Association with Obesity in Egyptian School Adolescents. Int $\mathrm{J}$ Hypertens [Internet]. 2011;2011:1-8. Available from: http://www.hindawi.com/journals/ijhy/2011/ 952537/

4. Falkner B, Daniels SR. Summary of the Fourth Report on the Diagnosis, Evaluation, and Treatment of High Blood Pressure in Children and Adolescents. Hypertens (Dallas, Tex 1979). 2004 Oct;44(4):387-8.

5. Chobanian A V, Bakris GL, Black HR, Cushman WC, Green LA, Izzo JL, et al. The Seventh Report of the Joint National Committee on Prevention, Detection, Evaluation, and Treatment of High Blood Pressure: the JNC 7 report. JAMA. 2003;

6. James P a, Oparil S, Carter BL, Cushman WC, Dennison-Himmelfarb C, Handler J, et al. 2014 evidence-based guideline for the management of high blood pressure in adults: report from the panel members appointed to the Eighth Joint National Committee (JNC 8). JAMA. 2014;

7. Stergiou GS, Giovas PP, Kollias A, Rarra VC, Papagiannis J, Georgakopoulos D, et al. Relationship of home blood pressure with target-organ damage in children and adolescents. Hypertens Res. 2011;

8. Urbina EM, Khoury PR, Mccoy C, Daniels SR, Kimball TR, Dolan LM. Cardiac and Vascular Consequences of PreHypertension in Youth. J Clin Hypertens. 2011;

9. Chiolero A, Bovet P, Paradis G. Screening for elevated blood pressure in children and adolescents: a critical appraisal. JAMA Pediatr. 2013;

10. National High Blood Pressure Education Program Working Group on High Blood Pressure in Children and Adolescents. The fourth report on the diagnosis, evaluation, and treatment of high blood pressure in children and adolescents. Pediatrics. 2004;

11. Lu Q, Ma CM, Yin FZ, Liu BW, Lou DH, Liu XL. How to simplify the diagnostic criteria of hypertension in adolescents. $\mathrm{J}$ Hum Hypertens. 2011;

12. Xi B, Zhang M, Zhang T, Li S, Steffen LM. Simplification of childhood hypertension definition using blood pressure to height ratio among US youths aged 8-17 years, NHANES 1999-2012. Int J Cardiol. 2015;

13. von Elm E, Altman DG, Egger $M$, Pocock SJ, Gøtzsche PC, Vandenbroucke JP. The Strengthening the Reporting of Observational Studies in Epidemiology (STROBE) statement: guidelines for reporting observational studies. J Clin Epidemiol [Internet]. 2008 Apr [cited 2014 Oct 6];61(4):344-9. Available from: http://www.ncbi.nlm.nih.gov/pubmed/18313 558

14. Buderer NM. Statistical methodology: I. Incorporating the prevalence of disease into the sample size calculation for sensitivity and specificity. Acad Emerg Med [Internet]. 1996 Sep;3(9):895-900. Available from: http://www.ncbi.nlm.nih.gov/pubmed/88707 64

15. Afsana F, Latif ZA, Maksumul Haq M. Parameters of metabolic syndrome are markers of coronary heart disease - An observational study. Int J Diabetes Mellit. 2010;

16. Rabbia F, Rabbone I, Totaro S, Testa E, Covella M, Berra E, et al. Evaluation of blood pressure/height ratio as an index to simplify diagnostic criteria of hypertension in Caucasian adolescents. Journal of Human Hypertension. 2011.

17. Egyptian Ministry of Health and Population. Egyptian national guideline of family medicine Volume 1 [Internet]. 2016. Available from: http://www.mohp.gov.eg/UserFiles/LibraryF iles/339699.pdf

18. Safari S, Baratloo A, Elfil M, Negida AS. Part 2: Positive and negative predictive values of diagnostic tests. Emerg (Tehran, Iran) [Internet]. 2015 Jun 16;3(3):87-8. Available from: http://journals.sbmu.ac.ir/emergency/article/ view/9199

19. Ahmed A, Ali SW, Massodi S, Bhat MA. Blood Pressure-to-Height Ratio as a Screening Tool for Hypertension in Children. Indian Pediatr [Internet]. 2016 Feb;53(2):137-9. Available from: http://www.ncbi.nlm.nih.gov/pubmed/26897 146

20. Xi B, Zhang M, Zhang T, Liang Y, Li S, Steffen LM. Hypertension Screening Using Blood Pressure to Height Ratio. Pediatrics. 
2014;

21. Galescu O, George M, Basetty S, Predescu I, Mongia A, Ten S, et al. Blood Pressure over Height Ratios: Simple and Accurate Method of Detecting Elevated Blood Pressure in Children. Int $\mathrm{J}$ Pediatr. 2012;

22. Dong B, Wang Z, Wang H-J, Ma J. Blood pressure-to-height ratio for screening prehypertension and hypertension in Chinese children. J Hum Hypertens [Internet]. 2015 Oct;29(10):618-22. Available from: http://www.ncbi.nlm.nih.gov/pubmed/25631 223

23. Amin M, Hussein N, Ashraf Sherif, Mohamad E. Screening of Body Mass Index (BMI) and Blood Pressure in Egyptian School Children. Med. J. Cairo Univ., Vol. 77, No. 3, June: 163-172, 2009 www.medicaljournalofcairouniversity.com 24. Morad M.M, Hagras A.M., Elnoaman A.A EA. Blood pressure versus anthropometric measures in Egyptian children aged 6-12 years (MD Thesis). Faculty of Medicine, Cairo University; 2004. 25. Ambarita K, Ramayani OR, Lubis M, Fujiati II, Ramayati R, Rusdidjas R. Blood pressure-to-height ratio for diagnosing hypertension in adolescents. Paediatr Indones. 2017;57(2):84-90.

26. Guo X, Zheng L, Li Y, Zhang X, Yu S, Sun Y. Blood pressure to height ratio: A novel method for detecting hypertension in paediatric age groups. Paediatr Child Heal. 2013;

27. Kelishadi R, Bahreynian M, Heshmat R, Motlagh ME, Djalalinia S, Naji F, et al. Accuracy of Blood Pressure-to-Height Ratio to Define Elevated Blood Pressure in Children and Adolescents: The CASPIANIV Study. Pediatr Cardiol. 2016;

28. Duarte JA, Guerra SC, Ribeiro JC, Mota RC. Blood pressure in pediatric years (8-13 years old) in the Oporto region. Rev Port Cardiol orgao Of da Soc Port Cardiol Port $\mathbf{J}$ Cardiol an Off J Port Soc Cardiol. 2000;19(7-8):809-20.

29. Baratloo A, Safari S, Elfil M, Negida A. Evidence Based Emergency Medicine Part 3: Positive and Negative Likelihood Ratios of Diagnostic Tests. Emergency; Vol 3, No 4 Autumn. 2015;

30. Deeks JJ, Altman DG. Diagnostic tests 4: likelihood ratios. BMJ. 2004;329(7458):1689. 